\title{
Human Resource Management Practices and Reflective Organizational Performance-A Focus on Public Offices of Ambo Town, Oromia, Ethiopia
}

\author{
Daniel Tadesse Tulu ${ }^{1} \quad$ Mekonen Gulilat ${ }^{2}$ \\ 1.Ambo University, Department of Management \\ 2.MBA graduate from Ambo university, Department of Management
}

\begin{abstract}
The study to examine human resource management practices vis-a-vis organization performance in the case of public organizations in Ambo town. The finding of the study indicated there is a positive relationship between recruitment and selection, training and development, performance appraisal and reward system, and organizational performance. Major challenges observed were lack of sufficient budget, absence of accountability and transparency, technological resistance, uncomfortable working environment, insufficient managerial capacity building and lack of employee inspiration. Management of Ambo Town public service offices need to ensure human resource activities are smartly done to unleash the potential of the offices.
\end{abstract}

Keywords/phrases: Human resource, Organizational performance, Public offices, Ambo

DOI: $10.7176 / \mathrm{JAAS} / 68-07$

Publication date:September $30^{\text {th }} 2020$

\subsection{Introduction}

Organization is a collection of people work together to achieve the same goal. The role of human resource is indispensable in this regard (Becker and Gerhart, 1996) and (Mahapatro, 2010). Human Resource Management (HRM) is activities related to human resources from entry to exit in an organizational arena (Armstrong, 2010). HRM deals with resources like knowledge, skills, abilities, creativity, etc of all employees (Nair and Rao, 1990). Still some organizations see HRM as intermingling of activities from task analysis to employee development, conflict management, employee reward, and employee safety and health, and how these activities are managed to achieve organizational (Raymond et.al, 2011).

In Ambo town public organizations, it is observed that employees criticize that they are not satisfied in terms of corruption in recruitment and selection process, intermittent training and development. Furthermore, there are no clear standardized criteria to evaluate high performer employee, rather it primarily focused on paper work. Some employees witness that there are no amenable reward practices in the Ambo town public organizations. Due to these aforementioned factors talented employees are leaving to private and non-governmental organizations for better environment and engagement. Hence, taking these problems in to account, this study intended to assess the HRM practices and organization performance in Ambo town.

\subsection{Objective of the Study}

The general objective of the study is to analyze the effect of human resource practices and organizational performance in Ambo town. Specifically, the study objectives are;

1. To assess the current practices of HRM in public organizations in the town.

2. To pinpoint the challenges in HRM in public organizations in the town.

3. To examine the effect of HRM practices on organizational performance in public organizations in the town.

\subsection{Empirical Literatures}

Several studies have been carried out on HRM practices of organizations in different countries. For instance, Kumar (2007) found that training, orientation, compensation, working environment, performance appraisal and promotion have impacts on organizations performance Edger and Geare (2005); and Paauwe and Richardson (1997) on their part indicated that better management of human resource activities leads to better organizational performance.

According to Syed and Yan (2012) found job rotation has high association with god performance of human resources in terms of Knowledge, skill and attitude in telecom industry. Gardner et al. (2003) revealed that if human resources are handled in a better way, there is a tendency by which organizational engagement is boosted. It is because when employees treated well they start to develop a sense of belongingness to organization which in other words implies organizational commitment.

According to Sundararajam (2007) and (Saraswathi, 2010) exhibited employees are positively looking for training and development as good human resource management practice is a pillar for organizational survival and 
growth. Shah et.al, (2012) cited in Janjua \&Gulzar (2014) suggested that training has a significant effect specifically on employee development and organizational performance in general

The study conducted by Tarekegn (2013) underscores the importance of human resource management practices in Ethiopia. It is suggested that HRM is strategic in nature and nees to be handled smartly. Ijigu (2015); Singh and Kassa (2016) and Asfaw, et.al, (2015) revealed that recruitment and selection, training and development, performance appraisal and compensation package have a significant positive impact on job satisfaction.

\subsection{Research methodology}

The research approach used for this study is a quantitative and qualitative research approach. It enables for triangulating and to look at many approaches for collecting and analyzing data rather than subscribing to only one way (Creswell, 2008) and (Johnston, 2010).

The study applied both descriptive and explanatory research design in an effort to examine the relationship between human resource management (HRM) practices and organizational performance (OP).

\subsubsection{Population and source of data}

In order to get sufficient and relevant information the study used both primary and secondary data sources. The primary sources of data were gathered from the respondents currently working in their respective public offices. Secondary data sources were gathered through published and unpublished documents of the offices. Apart from this, human resource management guidelines and training manuals were used. The target population is employees of Ambo town public offices. These include heads of the office, team leaders, experts and supportive staff employees. The target population of the study is 305 .

\subsubsection{Sampling Technique and Sampling Size}

The study used stratified sampling technique. Public organization in study area are divided in to three strata namely, economic sectors, social sectors and administrative sector and from these stratum 3 organizations are selected from each by simple random sampling technique. Total of 9 offices were selected namely Public service and human resource, Education office, Culture and Tourism office, Urban Development and House office, Municipality office, Government Communication affairs, Trade and Market Development, Finance, Agency of Urban Land Management. Sample respondent are selected using simple random sampling (lottery method).

Sample size was determined by using (Taro, 2006). In the following formula, $\mathrm{n}=$ the sample size, $\mathrm{N}=$ the study population, $\mathrm{e}=$ the level of precision

$$
n=\frac{N}{1+N(e)^{2}}
$$

Therefore, 173 respondents were used as sample for this study to gather data through questionnaire.

1.4.3 Data Collection Instrument

As instrument structured questionnaire and interview was prepared. The questionnaire consists of questions including practices of HRM, challenges encountered in HRM as well as performance public organization in the study area. The questions were based on a five point likert scale ranging from $1=$ strongly disagree, $2=$ disagree, $3=$ neutral, $4=$ agree and $5=$ strongly agree used in the questionnaire. Open ended questions were asked for the interview. During the interview continuous probing was done so as to get intended data.

1.4.4 Data Analysis Method

Both descriptive and inferential statistics were used in analyzing data. Descriptive statistics was employing by using mean, percentage, and standard deviations. For Inferential statistics tools like Pearsons correlation and multiple regression analysis were used to determine organizational performance by using the following model.

Where

$$
Y=\propto+\beta 1 x 1+\beta 2 x 2+\beta 3 x 3+\beta 4 x 4+\epsilon
$$

$\boldsymbol{Y}=$ performance of public organizational

$\alpha=$ constant

$\boldsymbol{x} \mathbf{1}=$ Recruitment and selection

$\boldsymbol{x} \mathbf{2}=$ Training and development

$\boldsymbol{x} \mathbf{3}=$ Performance appraisal

$\boldsymbol{x} \mathbf{4}=$ Rewards system

$\boldsymbol{\beta} 1-\boldsymbol{\beta} 4-$ are the coefficients associated with each independent variables.

\subsection{Result and Discussion}

To check the reliability of the scale and internal consistency of the measure, the study used the cronbach's Alpha method. Most commonly accepted value is 0.70 . As it should be equal to or higher than to say internal reliability prevails as shown on table1 below. 
Table 1: Cronbach's Alpha result

\begin{tabular}{lll}
\hline Scale & No. of Items & Cronbach's Alpha $(\alpha)$ \\
\hline 1. Recruitment and Selection & 5 & 0.845 \\
2. Training and Development & 7 & 0.842 \\
3. Performance Appraisal & 5 & 0.776 \\
4. Reward & 5 & 0.859 \\
\hline
\end{tabular}

Source: Survey data (2018)

\section{Challenges of Human Resource Management Practice in Public organization}

There were some challenges that encountered in public organization in the practice of human resource management practices indicated in the table below.

Table 2: challenges of human resource management

\begin{tabular}{|l|l|l|l|}
\hline \multicolumn{1}{|c|}{ Item } & $\mathrm{N}$ & Mean & Std. Deviation \\
\hline Lack of human resource planning & 138 & 3.11 & 1.194 \\
\hline There is no proper recruitment process & 138 & 3.21 & 2.665 \\
\hline There is no clear selection procedures & 138 & 3.04 & 1.123 \\
\hline In adequate training and development & 138 & 3.78 & 2.857 \\
\hline There is problems of promotion & 138 & 3.41 & 1.105 \\
\hline The evaluation criteria and process is not transparent & 138 & 2.96 & 1.155 \\
\hline There is no positive work environment & 138 & 2.33 & 1.172 \\
\hline There is no sufficient financial resources For HRM practices & 138 & 3.45 & 1.184 \\
\hline Feedback process is missed up in evaluation process & 138 & 2.85 & 1.306 \\
\hline Employee turnover is high & 138 & 2.88 & 1.211 \\
\hline Lack enforcement and accountability & 138 & 2.96 & 1.235 \\
\hline Lack of proper merit system & 138 & 3.38 & 1.228 \\
\hline Appointment to the position is not based on competencies & 138 & 3.22 & 1.202 \\
\hline Political affiliation is one problem for better HRM Practices & 138 & 3.46 & 1.280 \\
\hline Existence of conflict is high & 138 & 2.31 & 1.260 \\
\hline
\end{tabular}

Source: Survey data (2018)

As indicated on the above tables 2 on the challenges of human resources practices were identified and questions were posed to each sampled respondents. Accordingly different human resource management challenges are illustrated which include, inadequate training and development, there is problems of promotion, there are no sufficient financial resources for HRM practices, and Political affiliation is one problem for better HRM Practices. On these stated problems the sampled employee's respondent with mean 3.78, 3.41, 3.45, 3.38 and 3.46 respectively agreed as the problem exists in public organization in Ambo town. Respondents that neutral i.e uncertain with the problem describe which includes lack of human resource planning, there is no proper recruitment process ,there is no clear selection procedures ,the evaluation criteria and process is not transparent, feedback process is missed up in evaluation process, employee turnover is high, lack enforcement and accountability and appointment to the position is not based on competencies. But respondent disagreed on problems mentioned which includes there is no positive work environment and existence of conflict is high.

The study corroborates with (Habib,2012); (Wachira, 2012) and (Gebrekidan, 2011 human resource Management faces lack of comprehensive human resource strategies, lack of technology, poor climate and lack of sufficient .

From response of interview participants, major challenges observed in public organizations in Ambo are lack of sufficient budget for training and education, lack of accountability and transparency, poor of emphasis for professional development, poor environment for attracting and retaining qualified personnel, insufficient managerial capacity building and lack of employee motivation.

Table 3: organization performance

\begin{tabular}{lllr}
\hline \multicolumn{1}{c}{ Item } & N & Mean & Std. D \\
\hline The goal of my organization is achieved due to HRM practices & 138 & 3.51 & 1.148 \\
Customer Satisfaction is improved due to better HRM practices & 138 & 3.67 & 1.076 \\
Service delivery speed increase due to better HRM practices & 138 & 3.62 & 1.122 \\
Work place environment is improved due to better HRM practices & 138 & 3.64 & 1.170 \\
Grievances have been decreased due to HRM practices & 138 & 3.59 & 1.044 \\
Materials and budget are efficiently utilized due to HRM practices & 138 & 3.46 & 1.134 \\
HRM practices & 138 & 3.52 & 1.222 \\
\hline & \multicolumn{2}{c}{3.565} & \\
\hline
\end{tabular}

Source: Survey data (2018) 
According to table 3 on average, a mean of 3.57 was registered as pertaining to various performance aspects. The study findings specifically indicate that majority of the respondents agreed that their customer satisfaction is improved due to better HRM practices (3.67). Further, the findings indicate that majority of the respondents from the public organization of the town were their work place environment is improved due to better HRM practices, service delivery speed increase due to better HRM practices, grievances have been decreased due to HRM practices, overall performance of their organization is improved due to better HRM practices, organization has service based on the standards and the goal of their organization is achieved due to HRM practices3.64,3.62,3.59,3.52 and 3.51 respectively. However, the findings revealed that some respondent neutral that in their materials and budget are efficiently utilized due to HRM practices on public organization of the Ambo town (3.45). This indicates that human resource management practice was positively related to organizational performance.

Correlation analysis between HR practice and organizational performance

The results of this study confirm human resource practices in public organizations where influenced by several factors Recruitment and selection Practice (RES), Training and Development(TRD), Reward System Practices(REW) and performance appraisal(PA).Correlation analysis was performed to find out the influence of HR practice on organization performance.

The results of the relevant or appropriate correlation analysis are as outlined in table 4.11 below.

Based on the table below results of Pearson's correlation analysis indicated a statistically significant positive association between recruitment and selection and organization performance $(\mathrm{r}=0.464 ; \mathrm{p}<0.05)$ where recruitment and selection increased as the organization performance increases. The relationship between training and development and organization performance was positive, moderate and statistically significant $(\mathrm{r}=0.404 ; \mathrm{p}<$ 0.05). The relationship between performance appraisal on one hand and organization performance on the other was positive and statistically significant $(\mathrm{r}=0.360 ; \mathrm{p}<0.05)$. The relationship between reward system on one hand and organization performance on the other was positive and statistically significant $(r=0.399 ; \mathrm{p}<0.05)$. Interpretatively, recruitment and selection, training and development, performance appraisal and reward system were reflected considerable effect on performance of public organization in the study area. The other factor of $\mathrm{HR}$ practices, that is, challenges of human resource had a negative effect on public organizations' performance, their effect was very less. Therefore, Ambo town public organization ought to put greater focused on their recruitment and selection, training and development, performance appraisal and reward system in a systematic plan for achieving a particular goal in order to enhance their performance.

Table 4: Correlation analysis result

\begin{tabular}{|c|c|c|c|c|c|c|c|}
\hline & & RES & TRD & REW & PA & $\mathrm{CHA}$ & ORPR \\
\hline & Pearson Correlation & 1 & $.396^{* *}$ & $.341^{* *}$ & $.172^{*}$ & -.145 & $.464^{* *}$ \\
\hline \multirow[t]{3}{*}{ RES } & Sig. (2-tailed) & & .000 & .000 & .044 & .089 & .000 \\
\hline & $\mathrm{N}$ & 138 & 138 & 138 & 138 & 138 & 138 \\
\hline & Pearson Correlation & $.396^{* *}$ & 1 & $.298^{* *}$ & $.271^{* *}$ & -.162 & $.404^{* *}$ \\
\hline \multirow[t]{3}{*}{ TRD } & Sig. (2-tailed) & .000 & & .000 & .001 & .058 & .000 \\
\hline & $\mathrm{N}$ & 138 & 138 & 138 & 138 & 138 & 138 \\
\hline & Pearson Correlation & $.341^{* *}$ & $.298^{* *}$ & 1 & $.319^{* *}$ & -.064 & $.399^{* *}$ \\
\hline \multirow[t]{3}{*}{ REW } & Sig. (2-tailed) & .000 & .000 & & .000 & .458 & .000 \\
\hline & $\mathrm{N}$ & 138 & 138 & 138 & 138 & 138 & 138 \\
\hline & Pearson Correlation & $.172^{*}$ & $.271^{* *}$ & $.319^{* *}$ & 1 & $-.269^{* *}$ & $.360^{* *}$ \\
\hline \multirow[t]{3}{*}{ PA } & Sig. (2-tailed) & .044 & .001 & .000 & & .001 & .000 \\
\hline & $\mathrm{N}$ & 138 & 138 & 138 & 138 & 138 & 138 \\
\hline & Pearson Correlation & -.145 & -.162 & -.064 & $-.269^{* *}$ & 1 & -.151 \\
\hline \multirow[t]{3}{*}{ CHA } & Sig. (2-tailed) & .089 & .058 & .458 & .001 & & .077 \\
\hline & $\mathrm{N}$ & 138 & 138 & 138 & 138 & 138 & 138 \\
\hline & Pearson Correlation & $.464^{* *}$ & $.404^{* *}$ & $.399^{* *}$ & $.360^{* *}$ & -.151 & 1 \\
\hline \multirow[t]{2}{*}{ ORPR } & Sig. (2-tailed) & .000 & .000 & .000 & .000 & .077 & \\
\hline & $\mathrm{N}$ & 138 & 138 & 138 & 138 & 138 & 138 \\
\hline
\end{tabular}

Source: Survey data (2018)

As shown on the above table 4, RES was positively correlated with all variables except challenges that is negatively correlated that has coefficient of $0.396^{*} 0.341^{* *} 0.172^{*} 0-.145 \quad 0.464^{* *}$ with Training and Development, Reward System Practices, Performance appraisal, challenges, organizational performance. This implies that when recruitment and selection increases by one unit all the variables increases with the above coefficients while the challenges were inverse relationship to the recruitment and selection.

As a result of this study, it was found that a positive correlation between HRM practices and organizational 
performance. Whereas, the challenges of human resources mentioned were negatively correlated with organizational performance. In addition, HRM practices (recruitment and selection, training and development, reward review practices, and performance appraisal) all the variables were significantly positive correlated among each other.

The study also reveals that Recruitment and selections were also found to be strongly related to organizational performance. As a result the second hypothesis was accepted. Training and development also found to be strongly correlated to organization Performances. This also validates the third hypothesis as training and development has significantly influence the organizational performances. The studies also reveal Reward review and performance appraisal practices also significantly influence and positively relationship the organizational performance. This also makes the fourth and fifth hypothesis to be accepted. The last variable was challenges of HRM practice which influences the organizational performance negatively. Therefore the last hypothesis should reject.

Regression and Model Fitness

The linearity of the parameter is assumed since the model applies linear regression. The objective of the model is to predict the strength and direction of association among the dependent and independent variables. Thus, in order to maintain the validity and robustness of the regression result of the research in classical linear model (CLRM), it is better to satisfy basic assumption CLRM. That is, multicollinearity and autocorrelation.

Multicollinearity Test

Table 5: multicollinearity test

\begin{tabular}{|l|l|l|}
\hline \multicolumn{1}{|c|}{ Model } & \multicolumn{2}{c|}{ Co linearity statistics } \\
\cline { 2 - 3 } & Tolerance & VIF \\
\hline Recruitment and selection & .518 & 1.929 \\
\hline Training and development & .781 & 1.281 \\
\hline Performance appraisal & .677 & 1.476 \\
\hline Reward system & .673 & 1.487 \\
\hline
\end{tabular}

a. Dependent Variable: organization performance

Source: Survey Result 2018.

In multiple regression analysis, multicollinearity refers to a situation where a number of independent variables are closely correlated to one another. In order to test the existence of multicollinearity problem, VIF (Variance Inflation Factor) is utilized. Multicollinearity - tests whether there are perfect linear relationships among the explanatory variables or not. As a rule of thumb for multicollinearity test, the VIF and 1/VIF of the study shouldn't greater than 10 and less than 0.1 , respectively. The tolerance statistics, which is the reciprocal of VIF (1/VIF), also used to test multicollinearity. Tolerance values below 0.1 indicates serious multi-co linearity problem.

As indicated on table 6, the value of VIF does not exceed 10 and the value of tolerance is not below 0.1 . Therefore, in this study there is no multicollinearity problem existed among explanatory variables.

Autocorrelation Test

It is assumed that the errors are not correlated with one another. If the errors are correlated with one another, it would be stated that they are 'serially correlated'. A test of this assumption is therefore conducted. The first test was Durbin-Watson which is shown in the regression output of the model. As this test the values of DurbinWatson for the model 1.7005 are near to two.

Thus, there is no problem of autocorrelation.

Table 6: model summary

\begin{tabular}{|l|r|r|l|l|}
\hline Model & R & R Square & Adjusted R Square & Durbin-Watson \\
\hline 1 & $.608^{\mathrm{a}}$ & .628 & .535 & 1.7005 \\
\hline
\end{tabular}

Source: Survey data (2018)

The regression result explores the necessary indicters of the public organization performance by using the variables identified in the model. As indicated on table $6 \mathrm{R}^{2}$ value of 0.628 implies that about $62.8 \%$ of the changes in the public organization performance could only be explained explanatory variables (recruitment and selection, training and development, performance appraisal and reward system), while $37.2 \%$ of the change in organization performance is explained by other variables not included in the model of the study. 
Table 7: Coefficients ${ }^{a}$

\begin{tabular}{|c|l|r|r|r|r|r|}
\hline \multicolumn{2}{|l|}{ Model } & \multicolumn{2}{|c|}{ Unstandardized Coefficients } & Standardized Coefficients & \multirow{2}{*}{ Sig. } & \\
\cline { 3 - 8 } \multicolumn{2}{l|}{1} & B & Std. Error & Beta & & \\
\cline { 2 - 7 } & (Constant) & .528 & .580 & & .909 & .365 \\
\cline { 2 - 7 } & RES & .334 & .089 & .296 & 3.750 & .000 \\
\cline { 2 - 7 } & TRD & .187 & .083 & .177 & 2.240 & .027 \\
\cline { 2 - 7 } & REW & .177 & .077 & .181 & 2.302 & .023 \\
\cline { 2 - 8 } & PA & .218 & .085 & .571 & .011 \\
\hline
\end{tabular}

a. Dependent Variable: ORPR

Source: Survey data (2018)

Based on the above table 7, the following model was developed to examine the effect of human resource management practice on organization performance in this study. $\mathrm{OP}=0.528+0.334(\mathrm{RES})+0.187(\mathrm{TRD})+0.177(\mathrm{REW})+0.218(\mathrm{PA})+£$

Furthermore, the model summary also shows the significance of the model by the $p$ value statistics $(p=0.000)$ and $(\mathrm{F}=14.526)$ makes known the sound explanatory power of the model. This statistics indicates that the overall model is significant in explaining the dependent variable since the associated probability is lower than 0.05 .

The regression model output also reveals that the likelihood of organization performance increases as Recruitment and selection increases. The odds ratio indicate that, increasing the Recruitment and selection by one unit increases the probability of organization performance by nearly (.335) times other predictor variables being held constant in the model. Recruitment and selection was positively related with organization performance and significant at (.000) probability level.

The regression model output reveals that the likelihood of organization performance increases as Training and Development (TRD) increases. The coefficient indicate that, increasing the Training and Development (TRD) by one unit increases the probability of organization performance by nearly (.188) times other predictor variables being held constant in the model. So training and Development (TRD) was positively related with organization performance and significant at (.025) probability level. The regression model output reveals that the likelihood of organization performance increases as Reward System Practices (REW) increases. The coefficient indicate that, increasing the Reward System Practices (REW) by one unit increases the probability of organization performance by nearly (.176) times other predictor variables being held constant in the model. Therefore Reward System Practices was positively related with organization performance and significant at (.023) probability level. The regression model output indicated that the likelihood of organization performance increases as Performance appraisal (PA) increases. The coefficient indicates that, increasing the Performance appraisal (PA) by one unit increases the probability of organization performance by nearly (.218) times other predictor variables being held constant in the model. Performance appraisal (PA) was positively related with organization performance and significant at (.011) probability level

\section{Conclusions}

Human resource is the most crucial resource of any organization. Hence it is hard to think about organization without people. People perform every activities of an organization in coordinated manner. It is required that organizations need mechanism to stay employees satisfied (Mahapatro, 2010).

According to the findings, it is possible to conclude that recruitment and selection, training and development, performance appraisal, reward system and challenges of human resource practice significantly influenced the performance of public organization in Ambo town. Results of the inferential statistics such as regression coefficients show a positive effect on performance of public organization in the Ambo town.

There are challenges related government bodies at each level. The implementation of recruitment and selection are not free from intervention. This was also affirmed from key informants as public organizations sometimes hire people from different disciplines and political influences which may not fit the required jobs. It was also found that challenges such as inadequate training and development, there is a problem of promotion, there were no sufficient financial resources for HRM practices, there were no feedback practices for good performers and Political affiliation was the problem for better HRM Practices. The result from interview participant s also explain challenges of human resource practices like lack of sufficient budget for training and education, lack of accountability and transparency, lack of emphasis for professional development, accepting modern technological changes, creating an environment for attracting and retaining qualified personnel, insufficient managerial capacity building and lack of employees motivation were becoming great challenges for the effective practice of HRM in the public organizations.

In general, the findings of this research show that the effective HRM practices have great roles to influence public organization performance by playing a base position. There were challenges which influence the HR practice of public organization in the study area which can be solved in government body themselves. Therefore, it is important to draw some recommendations that can help to overcome the challenges of human resource practice 
there is a need for skilled man power and financial resources, to differentiate high performers and recognize their work and low performers support by providing the necessary technical and interpersonal to make perform increase organization performance.

\section{Recommendation}

The main interest of this paper was assessing the effects of human resource management practices on organization performance of public organization. On the basis of the major findings of the study, the following recommendations have been drawn with the view to improve the contributions of HRM practice on organization performance of public organization of the Ambo town.

$>$ It is better if the town public service and human resource office recruit and select the right person to the right place with responsible and accountable without any interference. This can be done to get effective performer employees which to achieve the organizational goal.

$>$ To insure the HR practices on organization performance especially recruitment and selection in public organization should be based on equal employment opportunity principle and without any intervention of political issue.

$>$ The public service and human resource office and administrative of the town should strengthen all public institutions in the town capacity at different levels (leader and expert), to play a major role in positively influencing the development of HRM practices on organizational performance.

$>$ To make HR competitive and successful, increasing the capacity, knowledge, and skill or attitude that enables the employee to prepare service activities through continuous trainings, experience sharing from successful public organization and experts.

$>$ Each management of public organization to invest in training and development of employees so as to increase human resource effectiveness and organization performance.

$>$ Reward is not practiced in the town so management of public organization to focus on the reward system with successful employee performance.

$>$ Responsible bodies should act to solve problems that the same qualification but different payment in the public organization of the town that influence the performance of the organization.

$>$ Responsible bodies should act to tackle the lack of sufficient budget for training and education, lack of accountability and transparency, lack of emphasis for professional development, accepting modern technological changes, creating an environment for attracting and retaining qualified personnel, insufficient managerial capacity building and lack of employees motivation.

Finally, investigating different HRM practices can be based on the right information are important for the good performance of public organization. This can be achieved by conducting more researches in related areas. The focus for this study was on the effect of HRM practice on organization performance of public organization in Ambo town. It is the researcher's view that future research could therefore investigate the other moderating variables such as employee turnover, management employee relation, employee retention, motivation factor and regulatory environment and come up with specific findings which will potentially contribute a lot in the public organization performance of the country in general.

Funding information/Conflict of Interest Declarations

The authors declared that there is no conflict of interest on the paper. There is no funding organization/individual.

\section{References}

Armstrong, M. (2010) 'A Hand book of Human Resource Management Practice', London: Kogen Page.7-23.

Asfaw, A. M., Argaw, M. D., \& Bayissa, L. (2015). The impact of training and development on employee performance and effectiveness: A case study of District Five Administration Office, Bole Sub-City, Addis Ababa, Ethiopia. Journal of Human Resource and Sustainability Studies, 3(04), 188.

Becker, B., \& Gerhart, B. (1996). The impact of human resource management on organizational performance: Progress and prospects. Academy of management journal, 39(4), 779-801.

Creswell, J. W., \& Garrett, A. L. (2008). The "movement" of mixed methods research and the role of educators. South African journal of education, 28(3), 321-333.

Edgar, F. and Geare, A. (2005). 'HRM practice and employee attitudes: different measures - different results. Personnel Review, 34, 534-49.

Gardner, S. D., Lepak, D. P., \& Bartol, K. M. (2003). Virtual HR: The impact of information technology on the human resource professional. Journal of Vocational Behavior, 63(2), 159-179.

Ijigu, A. W. (2015). The effect of selected human resource management practices on employees' job satisfaction in Ethiopian public banks. EMAJ: Emerging Markets Journal, 5(1), 1-16.

Janjua, B. H. \& Gulzar, A. (2014). The impact of human resource practices on employee commitment and employee retention in telecom sector of Pakistan: Exploring the mediating role of employee loyalty. IOSR 
Journal of Business and Management. 16(1). 76-81.

Johnston, A. (2010). Sampling hard-to-reach populations with respondent driven sampling: Methodological Innovations Online (2010) 5(2) 38-48.

Kumar Kalra, S. (2007). Human potential management: time to move beyond the concept of human resource management?.

Mahapatro, B. B. (2010). New Age: Human Resource Management. New Age International Publisher, Balasore, Orisa, 3-4.

Nair, M. R. R., \& Rao, T. V. (1990). Excellence Through Human Resource Development: Improving Productivity and Competitiveness.

Paauwe, J., \& Richardson, R. (1997). Introduction special issue on HRM and performance. International Journal of Human Resource Management, 8(3), 257-262.

Rao, P. S. (1990). Personnel/Human Resource Management: Text, Cases and Games. Delhi: Konark Publishers.

Raymond,A.Noe., John, R. Hollenbeck., Barry, Gerhart and Patrick M. Wright (2011).Fundamentals of Human Resource Management. New York: McGraw -Hill companies. Inc

Saraswathi, S., 2010. "Human Resources Development Climate: An Empirical Study," International Journal of Innovation, Management and Technology, 1(2), pp. 174-179.

Shah, F. A., Yusaff, R. M., Hussain, A., \& Hussain, J. (2012). A critical review of multinational companies, their structures and strategies and their link with international human resource management. Journal of Business and Management, 3(5), 28-37.

Singh, N. R., \& Kassa, B. (2016). The impact of human resource management practice on organizational performance-a study on Debre Brehan University. International Journal of Recent Advances in Organizational Behaviour and Decision Sciences, 1(1), 643-662.

Sundararajam, S.,(2007). Employee's Attitude towards Training and Development in private sector industries

Syed, N., \& Yan, L. X. (2012). Impact of high performance human resource management practices on employee job satisfaction: Empirical analysis. Interdisciplinary Journal of Contemporary Research in Business, 4(2), 318-342.

TAREKEGN, D. L. (2013). HISTORY OF HR MANAGEMENT PRACTICES IN ETHIOPIA.

Taro, Y. (2006). Basic Sampling Methods. Translation: Esin Aptekin, Bakir, M. Akif, Aydin Celal and Gurbuzsel Esen) Istanbul: Nobel Matbaacilik Ltd. Sti . 